\title{
The Effect of Covid-19 Pandemic on Liver Transplant Patients: a Single Center Report of 584 Cases
}

\author{
Altan Alim*, Burak Dal M, Erdogan Y, Guler N and Acarli K \\ Department of Liver Transplantation, Turkey
}

ISSN: 2637-7632

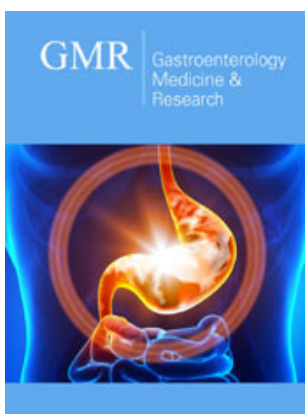

*Corresponding author: Altan Alim, Department of Liver Transplantation, Memorial Sisli Hospital, Istanbul, Turkey

Submission: 侮 July 13, 2020

Published: 制July 23, 2020

Volume 4 - Issue 5

How to cite this article: Altan Alim, Burak Dal M, Erdogan Y, Guler N, Acarl K. The Effect of Covid-19 Pandemic on Liver Transplant Patients: a Single Center Report of 584 Cases . Gastro Med Res. 4(5). GMR.000598. 2020.

DOI: $10.31031 /$ GMR.2020.04.000598

Copyright@ Altan Alim, This article is distributed under the terms of the Creative Commons Attribution 4.0 International License, which permits unrestricted use and redistribution provided that the original author and source are credited.

\begin{abstract}
It is claimed that, COVID-19 pandemic is mostly affecting people who have concomitant health problems and who are immunocompromised. By definition all transplant patients can be regarded as immunocompromised. We made a phone survey to understand the effect of this pandemic on our liver transplanted patients. This phone survey was performed between 1-5 June by our medical staff. We contacted 584 of our patients and asked them a specific set of questions. COVID-19 infection was found only in 4 of $584(0,7 \%)$ transplanted patients. There was no mortality. Almost $50 \%$ of patients did not have any concern or fear from COVID-19 infection. Most of them define themselves compliant with rules like social distancing, mask wearing and hand washing. 98\% of the patients didn't have any difficulty to reach to medical assistance and thought to manipulate their immunosuppressive dosages. Our phone survey showed that so far COVID-19 infection among immunosuppressive patients is not a bigger problem compared to normal population. And universal rules as social distancing mask and handwashing seems to be enough for prevention.
\end{abstract}

Keywords: COVID-19; Liver transplantation; SARS Pandemic

\section{Introduction}

A novel coronavirus which causes COVID-19 infection in humans was identified in December 2019 in Wuhan city, Hubei province, China [1]. Since than the illness has rapidly spread throughout the world that the World Health Organization (WHO) declared COVID-19 as a global Pandemic on March 11, 2020. WHO has reported that as of 27 May 2020 there have been 5,491,678 confirmed cases of COVID-19, including 349,190 deaths throughout the world. It is believed that the estimated mortality rate is approximately $2 \%$, but thru rate may vary [2]. And according the actual WHO numbers above, the mortality is as high as 6\%. In Turkey, the very first case is tested positive on 11 Marche 2020. The first death due to COVID-19 in the country occurred on 15 March 2020 and by 1 April, it was confirmed that COVID-19 had spread all over Turkey. On 14 April 2020, the Turkish Ministry of Health announced that the spread of the virus in Turkey has reached its peak in the fourth week and started to slow down. Since the middle of March there is curfew for people $<20$ and $>65$ years of age. As of 27 May 2020, it is reported that there have been 159,797 confirmed COVID-19 cases and 4,431 deaths in Turkey with a calculated mortality rate of $2,8 \%$. And still around 1000 new cases encountered daily. On the other hand, since as policy, only symptomatic patients and his contacted persons are tested, it is believed that the actual number of COVID-19 patients might be higher. Since organ transplantation activities such as elective surgeries are slowed down or stopped [3] to prevent any further spread of the disease. In countries like Turkey where almost $80 \%$ of liver transplant activity is performed from living donors, there is double fold risks, for recipient and donors. To be on safe side almost in every country and every transplant center guideline have been published for issues to liver transplantation. But we all know, that stopping or slowing down all transplant activities can prevent some problems in new transplanted patients; but, thousands of transplanted recipients are living among the population immunosuppressed, concerned, afraid and even without specific recommendations from major societies to calm 
them down. Bhoori and coworkers newly reported their experience in the midst of the current outbreak in Lombardy, Italy. Three of their 111 long-term liver transplant survivors (transplanted more than 10 years ago) died following severe COVID-19 disease [4]. There is no enough data on COVID-19 in liver transplant patients. To address this issue, we conducted a survey among the liver transplant patients and their families. The aim of the study are, to find out the prevalence and mortality of this COVID-19 infection among liver transplant patients, how they were acting in the middle of this pandemic to prevent themselves from the infection, evaluate their level of anxiety, difficulty to reach any medical help and any concern about adjusting or stopping their immunosuppressive medication.

\section{Material and Methods}

All liver transplant survivors from our Center who have Turkish nationality, are contacted by 3 members of our team by phone between 1st and 5th of June. They all are asked the same questions. The questions are about: their compliance with social distancing rules and national curfew decisions, COVID-19 diagnosis, where they have been treated, existence of any COVID-19 (+) family members in the house, existence of any COVID-19 (+) relatives, the level of their anxiety about themselves regarding COVID-19 infection, difficulty to access medical advice (to reach us or other doctors) and whether they had any thought about stopping or lowering the immunosuppressive therapy.

\section{Results}

Between 2006 and 2019, 1203 liver transplantations have been performed in Memorial Sisli Hospital, Istanbul. Almost 80\% of transplantations are from living donor. Among these 31,7\% (372) were pediatric patients. One, 5 and 10 years survival are 85,8\%, $78,8 \%$ and $74,9 \%$, respectively. During this pandemic there was curfew for persons $<20$ and $>65$ almost as long as 2,5 month. For others curfew was announced for weekends and holidays. Also, major cities, among them as epicentre of the pandemic Istanbul was on lockdown. 584 patients (358 male, 226 female) or families are reached in this short period of time. $33,4 \%$ of the patients were pediatric ( $<18$ years) and 66,6\% were adults. $108(18,5 \%)$ of the patients were $\geq 65$ years of age (considered risky group). Almost half of the patients $(283 ; 48,5 \%)$ were living in Istanbul (epicentre of pandemic in Turkey).

The result are as follows:

A. COVID-19 infection: Total number of COVID-19 (+) patients are four $(0,7 \%)$; Three of them diagnosed with symptoms an (+) PCR test, one is diagnosed based on clinical findings (Lung CT, fever...). None of them died.

B. Compliance to curfew or social distancing: 562 patients can regard as full compliant. They stayed home, avoided unnecessary contact, wear masks. Among this group there were two diagnosed patients. Amon less compliant 22 cases (needed to go out, to work, less social distancing, etc.) only one patient was COVID-19 (+).

C. Covid-19 treatment: Two patients got COVID-19 treatment at home alone. One started to treatment at home but needed hospitalization, one patient was hospitalized to begin with. But all are cured.

D. Effect of close contact: Seven patients had COVID-19 (+) family members in the same house. Three out of this seven tested also COVID -19 (+).

E. Anxiety level: 229 patients (39,2\%) didn't feel worried at all and they were full compliant to the prevention rules. There was no detected COVID-19 positivity among them. 94(16\%) patients were a little bit worried. They also define themselves less compliant. There was one COVID-19 diagnosed patient in this group. 261(44,7\%) patients defined themselves worriers. There of them found COVID-19(+).

F. Medical assistance: Almost all patients (98\%) did not have any difficulties to reach any medical assistance.

G. Immunosuppressive treatment: None of the patients have thought about changing or stopping their regimen.

\section{Discussion and Conclusion}

According to the findings of our phone survey among 584 long-term liver transplant patients, we can conclude that, despite our expectations and fears, the frequency of COVID-19 positivity among these patients remained low ( 4 out of $584 ; 0,7 \%$ ). There is no mortality so far. Apparently almost all (96\%) were aware of the importance of isolation and protection and showed compliance to protective rules. They were able to reach any medical assistance and therefore most of them did not worry too much for themselves.

\section{Ethical Statement}

Ethics committee approval was obtained from the Local Ethical Committee of Sisli Memorial Hospital. The study was conducted according to the criteria of the Declaration of Helsinki and the Declaration of İstanbul.

\section{References}

1. Zhu N, Zhang D, Wang W, Li X, Yang B, et al. (2020) A novel coronavirus from patients with pneumonia in China, 2019. N Engl J Med 382(8): 727733.

2. Lipsitch M, Donnelly CA, Fraser C, Blake IM, Cori A, et al. (2015) Potential biases in estimating absolute and relative case-fatality risks during outbreaks. PLoS Negl Trop Dis 9(7): e0003846.

3. Filipe SC (2020) Liver transplantation in an ICU dominated by COVID-19. Liver Transpl.

4. Bhoori S, Rossi RE, Citterio D, Mazaferro V (2020) COVID-19 in longterm liver transplant patients: Preliminary experience from an Italian transplant centre in Lombardy. Lancet Gastroenterol Hepatol 5(6): 532533.

For possible submissions Click below: 